\title{
Integrated Biocatalytic Platform Based on Aqueous Biphasic Systems for the Sustainable Oligomerization of Rutin
}

\author{
Abel Muñiz-Mouro, Ana M. Ferreira, João A. P. Coutinho, Mara G. Freire, Ana P. M. Tavares,* \\ Patricia Gullón, Sara González-García, and Gemma Eibes*
}

Cite This: ACS Sustainable Chem. Eng. 2021, 9, 9941-9950

Read Online

\section{ACCESS | Lill Metrics \& More | 回 Article Recommendations ｜（） Supporting Information}

ABSTRACT: Rutin is a known antioxidant compound that displays a broad range of biological activities and health-related benefits but presents a low water solubility that can be overcome by its polymerization. In this work, biocompatible aqueous biphasic systems composed of the ionic liquid cholinium dihydrogen phosphate $([\mathrm{CH}][\mathrm{DHph}])$ and the polymer poly(ethylene glycol) 600 (PEG 600) were investigated as an efficient integrated reaction-separation platform for the laccase-catalyzed oligomerization of rutin. Two different approaches were studied to

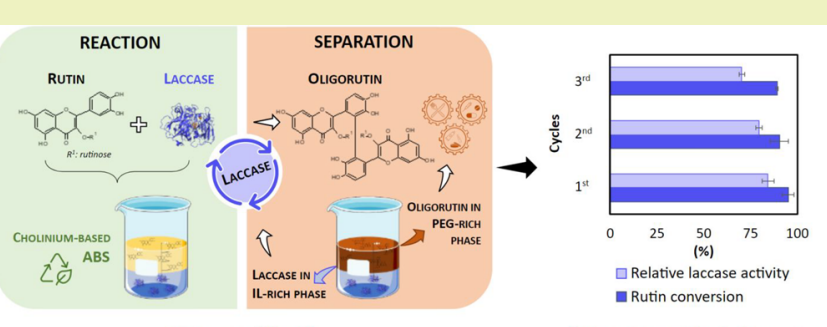
reuse laccase in several oligorutin production cycles, the main

difference between them being the use of monophasic or biphasic regimes during the oligomerization reaction. The use of a biphasic regime in the second approach (heterogeneous reaction medium) allowed the successful reuse of the biocatalyst in three consecutive reaction-separation cycles while achieving noteworthy rutin oligomerization yields (95\% in the first cycle, $91 \%$ in the second cycle, and $89 \%$ in the last cycle). These remarkable results were caused by the combination of the increased solubility of rutin in the PEGrich phase together with the enhanced catalytic performance of laccase in the $[\mathrm{Ch}][\mathrm{DHph}]$-rich phase, alongside with the optimization of the $\mathrm{pH}$ of the reaction medium straightly linked to enzyme stability. Finally, a life-cycle assessment was performed to compare this integrated reaction-separation platform to three alternative processes, reinforcing its sustainability.

KEYWORDS: Rutin oligomerization, Organic-free, Biocompatible, Laccase reuse, Aqueous biphasic system, Life-cycle assessment

\section{INTRODUCTION}

Rutin (2-(3,4-dihydroxyphenyl)-5,7-dihydroxy-4-oxo-4H-chromen-3-yl 6-O-(6-deoxy- $\alpha$-L-mannopyranosyl)- $\beta$-D-glucopyranoside) is a flavonoid compound present in fruits, vegetables, and plant-derived beverages. ${ }^{1}$ Traditionally used in Chinese medicine, ${ }^{2}$ this substance exhibits valuable antioxidant activities and interesting pharmacological properties that allow its use in the prevention of diseases such as cancer, diabetes, and cardiovascular and neurodegenerative conditions. ${ }^{3}$ Due to its antioxidant features, rutin can also be used as a nutraceutical compound. Up to date, the Dietary Supplement Label Database contains more than 1320 marketed products with rutin as one of these ingredients. ${ }^{4}$ However, despite its interesting biological properties, the large-scale use of flavonoids such as rutin faces some challenges due to its poor thermal stability and low solubility in aqueous and nontoxic organic solvents. ${ }^{5}$ To overcome these drawbacks, the enzymatic modification of natural flavonoids by laccases (EC 1.10.3.2) and peroxidases (EC 1.11.1) has gained interest over the past decades, especially concerning laccases since they use oxygen as a final electron acceptor rather than hydrogen peroxide. ${ }^{6}$ These oxidative enzymes catalyze the formation of phenoxyl radicals that, following a further oxidative coupling, lead to the production of higher molecular weight poly- phenols, ${ }^{7}$ improving the solubility, stability, and, in some cases, the bioactive properties of phenolic compounds like rutin. ${ }^{8}$

Although the laccase-catalyzed polymerization of rutin is a promising strategy, since it allows the control of the polymer structure by the nature of the reaction medium, while being carried at mild conditions of temperature, $\mathrm{pH}$, and pressure, the biocatalyst currently represents one of the highest costs of the process. Therefore, to boost the economic viability of these biocatalytic processes, the immobilization of enzymes in solid supports and their reuse has been the target of intensive investigation. ${ }^{10}$ However, the conventional enzyme immobilization techniques present some drawbacks, such as mass transfer limitations (in entrapment or encapsulation), the use of toxic compounds as a cross-linking agent (for both adsorption on solid supports and cross-linked enzyme aggregates), enzyme leaching (in solid supports adsorption), and enzyme inactivation due to modifications of the protein

Received: $\quad$ May 21, 2021

Revised: July 2, 2021

Published: July 14, 2021 
structure and changes in its active site (covalent binding). ${ }^{11}$ Hence, there is the need to find alternative, biocompatible, and enzyme-friendly reaction media which simultaneously allow the reuse of the biocatalyst in multiple production steps. Along this line, integrated biocatalytic systems can be seen as promising approaches toward large-scale integration. ${ }^{12}$

Liquid-liquid (L-L) biphasic systems are an attractive option since they can allow the integration of the reaction and separation steps without implicating the above-mentioned drawbacks of enzyme immobilization techniques. Indeed, previous works on biocatalytic processes in biphasic systems composed of water-organic solvents (and, in some cases, surfactants) have reported remarkable results. ${ }^{13}$ Regarding the specific performance of laccase in biphasic systems, this enzyme has been used in the degradation of polluting aromatic compounds (namely estradiol and anthracene), observing an increase in substrate solubility that consequently promoted mass transfer, enhancing the overall substrate conversion. ${ }^{13,14}$ Thus, these works suggest that the laccase-catalyzed oxidation of hydrophobic substrates can be positively affected by the presence of a more hydrophilic phase, where laccase is preferentially solubilized, and a hydrophobic phase that enhances the substrate solubility.

To avoid the use of volatile organic compounds, since some of them can be toxic and consequently compromise the final application of the products as nutraceuticals, aqueous biphasic systems (ABS) may be investigated as compatible media for biocatalyzed processes. ABS are ternary systems comprised of two immiscible water-rich phases, formed by mixing water and two phase-forming compounds (e.g., polymer-polymer, polymer-salt, or salt-salt). Although the potential of ABS for the purification of cells, proteins, enzymes, and other biomolecules has been extensively studied, ${ }^{15}$ their use in biocatalytic processes has not been deeply investigated. Concerning laccase, various works have been reported regarding the use of $\mathrm{ABS}$ for its purification, ${ }^{16}$ but only one previous research study focused on the use of these systems as an integrated reaction-separation platform allowing enzyme reuse. ${ }^{17}$ This work was the first step to show the viability of ABS for laccase-catalyzed processes, demonstrating (as a proof of concept) the feasibility of thermoreversible ABS (composed of two different zwitterions and poly(ethylene glycol) 6000 (PEG 6000)) in performing the oxidation of ABTS (standard substrate for laccase used to evaluate its activity) in a homogeneous regime ABS, followed by laccase and oxidized substrate separation toward opposite phases, which occurred due to an increase/decrease in temperature. ${ }^{17}$ When studying laccase purification, Silvério et al. ${ }^{16}$ analyzed different polymer-polymer and polymer-salt-based ABS, observing that polymer-salt ABS led to better results concerning both laccase extraction and stability and showing that $A B S$ based on poly(ethylene glycol) (PEG) and phosphate salt combinations could lead to promising results and hence should be further investigated in the future. Moreover, Capela et al. ${ }^{18}$ analyzed laccase purification and activity in IL-based ABS, identifying cholinium-based ILs as promising candidates for ABS formulation regarding both enzyme extraction and activity.

Recently, PEG-IL-based ABS have been investigated with the aim of combining the biocompatibility and low toxicity of PEGs, which are authorized food additives in the European Union according to Regulation (EC) No. 1333/2008, ${ }^{19}$ with the increased efficiency and selectivity of the separation step associated with IL-based ABS, while also decreasing the viscosity of the media when compared to polymer-based ABS. $^{20}$

Based on the need for a sustainable reaction-separation process for the laccase-based oligomerization of rutin, especially focused on the reuse of the biocatalyst (since it is the most expensive product required in the reaction), this work aims to investigate the use of PEG-IL-based ABS. Laccase from the ligninolytic fungus Trametes versicolor was used. Considering that the final application of oligorutin would be the formulation of food additives, cosmetic products, or its use in pharmaceutical compounds, the toxicity should be taken into account when selecting a reaction medium. Accordingly, different cholinium-based ILs (with negligible toxicity and low cost of production $)^{20}$ were chosen in this work to be combined with PEG in the formulation of ABS. Two different approaches were studied to reuse laccase in several oligorutin production cycles, i.e., oligomerization reaction carried out in the monophasic or biphasic regime. Finally, a life-cycle assessment (LCA) was performed on the most promising approach and compared to three alternative processes in order to demonstrate the viability of the $A B S$ to be applied as a sustainable integrated reaction-separation platform for the production of oligorutin, a compound with potential commercial interest.

\section{EXPERIMENTAL SECTION}

Chemicals. Cholinium dihydrogen phosphate 99 wt \% pure ([Ch] $[\mathrm{DHph}])$ and cholinium acetate 98 wt \% pure $([\mathrm{Ch}][\mathrm{Ac}])$ were both purchased from IoLiTec (Ionic Liquids Technologies $\mathrm{GmbH}$ ). Cholinium glycolate $([\mathrm{Ch}][\mathrm{Gly}])$ was synthesized as described by Quental et al. ${ }^{21}$ Before use, all cholinium-based ionic liquids (ILs) were purified and dried for a minimum of $24 \mathrm{~h}$ at constant agitation, at moderate temperature $\left(\sim 50{ }^{\circ} \mathrm{C}\right)$, and under vacuum (to reduce their volatile impurities to negligible values). After this step, the purity of each IL was confirmed by ${ }^{1} \mathrm{H}$ and ${ }^{13} \mathrm{C}$ NMR spectra and found to be $>98 \%$. The polymer poly(ethylene glycol) (PEG) of average molecular weight $600 \mathrm{~g} \cdot \mathrm{mol}^{-1}$ (PEG 600) was supplied by Alfa Aesar and used as received. The chemical structures of such ILs and polymer are presented in Figure S1. Enzyme-catalyzed reactions were performed using commercial laccase from $T$. versicolor, and its activity was assessed using 2,2'-azino-bis(3-ethylbenzathiazoline-6-sulfonic acid) diammonium salt (ABTS) as the substrate, both acquired from Sigma. Potassium persulfate and Trolox (6-hydroxy-2,5,7,8tetramethylchroman-2-carboxylic acid) for antioxidant capacity measurements were purchased from Sigma. Rutin (rutin hydrate 98 wt $\%$ pure) was purchased from TCI (Thermo Fischer Scientific).

Laccase-Catalyzed Rutin Oligomerization Using ABS as a Reaction Medium. Based on our previous work, ${ }^{22}$ rutin oligomerization was performed under the catalytical activity of 1000 $\mathrm{U} / \mathrm{L}$ over $24 \mathrm{~h}$ and starting with an initial rutin concentration of $3 \mathrm{~g} / \mathrm{L}$ (where one unit, $\mathrm{U}$, is defined as the amount of laccase capable of oxidizing $1 \mu \mathrm{mol}$ of ABTS per minute). Reactions were performed in $15 \mathrm{~mL}$ falcon tubes filled with $4.25 \mathrm{~mL}$ of ABS $(5 \mathrm{~g})$ in constant agitation $(50 \mathrm{rpm})$ on a Multi Bio RS-24 agitator (BioSan) at $25{ }^{\circ} \mathrm{C}$. Agitation of $50 \mathrm{rpm}$ was chosen as a proper rotatory speed ${ }^{23}$ since it provided enough contact between the enzyme and the substrate, without implying an excess of stirring. The desired $\mathrm{pH}$ of the $\mathrm{ABS}$ was achieved through the careful addition of $10 \mathrm{M} \mathrm{NaOH}$ after mixing the polymer, the ionic liquid, and $90 \%$ of the distilled water, providing the lacking amount of water to reach $5 \mathrm{~g}$ of $\mathrm{ABS}$ after the $\mathrm{NaOH}$ addition. After rutin addition to the $\mathrm{ABS}$, the volume needed of a previously prepared and characterized stock solution of laccase from T. versicolor was supplied to start the synthesis of oligorutin.

Rutin depletion during the reaction was followed by HPLC (Shimadzu, PROMINENCE) allowing the calculation of the rutin conversion (also referred in this work as oligomerization yield), following the protocol and calculation fully described in the 
Supporting Information. Laccase activity was also spectrophotometrically assessed (Shimadzu, UV-1800) during the reaction following the protocol described by Zimmermann et al. ${ }^{24}$

Identical experiments to those involving $3 \mathrm{~g} / \mathrm{L}$ rutin but starting with an initial rutin concentration of $10 \mathrm{~g} / \mathrm{L}$ were additionally performed to explore the feasibility of the developed process to allow the enzymatic oligomerization of rutin at higher substrate concentrations.

Recovery and Laccase Reuse. Three consecutive cycles of oligorutin synthesis and phase separation were performed to assess the biocatalyst reusability and oligorutin extraction on ABS reaction media. After $24 \mathrm{~h}$ of reaction, the laccase activity and oligorutin concentration were measured, and the phase formation was quickly promoted by centrifugation at $25{ }^{\circ} \mathrm{C}$ for $30 \mathrm{~min}$ at $5000 \mathrm{rpm}$. Centrifugation was used in this lab-scale work both to ensure the thermodynamic equilibria of the aqueous phases and to standardize a phase-formation step for all experiments. However, a remarkably rapid phase formation was already observed in less than $10 \mathrm{~min}$ after stopping the stirring of the reaction media, thus confirming that a centrifugation step would not be strictly needed (which would positively affect the economic viability of larger-scale reactions). The oligorutin concentration was measured spectrophotometrically (Shimadzu UV-1800) following the developed protocol indicated in the Supporting Information. Laccase activity (U/L), oligorutin concentration $(\mathrm{mg} / \mathrm{L})$, and volume $(\mathrm{mL})$ were measured for both phases of the ABS, allowing the calculation of the total amount of oligorutin $(\mathrm{mg})$ and laccase $(\mathrm{U})$ in each phase and, subsequently, the calculation of the percentage extraction efficiencies (\%EE) for both product $\left(\% E E_{\text {oligorutin }}\right)$ and biocatalyst $\left(\% E E_{\text {laccase activity }}\right)$, defined as the ratio between oligorutin $\mathrm{mg}$ or laccase $U$ present in that specific phase and the total amount present in the complete ABS, respectively.

The oligorutin-enriched top phase was then removed, and the same volume of a new top polymer-rich phase with the exact same composition (determined by the tie-line) and $\mathrm{pH}$, but lacking oligorutin, was added over the remaining laccase-enriched bottom phase. Rutin was later added to reach a concentration of $3 \mathrm{~g} / \mathrm{L}$, and the mixture was shaken and placed in the Multi Bio RS-24 agitator, therefore starting a new oligorutin synthesis step. This process, graphically represented in Figure S2, was repeated for up to three complete reaction-separation cycles, thus leading to three separated oligorutin-enriched top phases and a final laccase-enriched bottom phase.

Recovery of PEG 600 and [Ch][DHph]. Aiming to explore the recovery of PEG 600 and $[\mathrm{Ch}][\mathrm{DHph}]$ present in the top oligorutinenriched phase, an ultrafiltration step was considered after phase separation. In this preliminary study, a $1 \mathrm{kDa}$ nominal pore size regenerated cellulose membrane was used to retain the produced oligorutin inside of a $10 \mathrm{~mL}$ ultrafiltration Amicon stirred cell (Millipore), while allowing both PEG 600 and [Ch][DHph] to pass through the membrane, therefore promoting the separation of oligorutin from the other chemicals present in the top phase. Two different aqueous dilutions of top phases $(1: 2$ and $1: 4 \mathrm{v} / \mathrm{v})$ were considered as inputs for this ultrafiltration cell since the original undiluted phase would lead to membrane fouling due to high viscosity, and ultrafiltration was promoted by an overpressure (3 bar) originated with $\mathrm{N}_{2}(\mathrm{~g})$, while maintaining the diluted sample under constant stirring. A final retentate volume equal to the original undiluted top phase volume was obtained in each case (therefore filtering $50 \%$ and $75 \%$ volume of $1: 2$ and $1: 4$ dilutions, respectively). The composition of both retentate and permeate streams was studied; the oligorutin concentration was spectrophotometrically measured following the protocol described in the Supporting Information, while the mass percentage of PEG $600+[\mathrm{Ch}][\mathrm{DHph}]$ in the retentate and permeate streams was calculated as the relation between the mass of a known volume of each stream after and before freeze-drying (withdrawing oligorutin mass from this value). Once these data were obtained, the recovery of PEG $600+[\mathrm{Ch}][\mathrm{DHph}]$ was calculated.

Oligorutin Characterization. Mass spectra of retentate and permeate products after ultrafiltration were determined by MALDI-
TOF (matrix-assisted laser desorption/ionization-time-of-flight) based on the protocol described by Anthoni et al., ${ }^{25}$ with the slight modifications indicated in the Supporting Information.

The antioxidant activity of the oligorutin produced in the three successive cycles involving laccase reuse was measured following the Trolox Equivalent Antioxidant Capacity (TEAC) protocol as described by Gullón et al., ${ }^{26}$ fully explained in the Supporting Information. Results were expressed in Trolox equivalents.

Environmental Assessment. LCA modeling was carried out in Simapro software $\mathrm{v}^{2} . \mathrm{N}^{27}$ and the CML $2001 \mathrm{v} 2.05$ method $^{28}$ developed by the Center of Environmental Science of Leiden University was used for the selection of the characterization factors required to estimate the environmental burdens, considering five impact categories: global warming (GW), acidification (AC), eutrophication (EU), ozone layer depletion (OD), and photochemical oxidation (PO).

The process developed in this work, scenario 1 (Sc1), was compared to other three scenarios involving laccase reuse for oligorutin production: Sc2, the same biphasic strategy considered as in our target system $(\mathrm{Sc1})$ but including the reuse of PEG 600 and $[\mathrm{Ch}][\mathrm{DHph}]$ by implementing an additional ultrafiltration step prior to freeze-drying; Sc3, the operation of an enzymatic membrane reactor (EMR) to reuse laccase for oligorutin synthesis; ${ }^{8}$ and Sc4, the use of laccase immobilized onto magnetic nanoparticles (mNPs) allowing its reuse in multiple synthesis steps. ${ }^{29}$

The comparative profile was performed following an attributional cradle-to-gate approach, including all stages performed in the lab from the preparation of the reaction medium up to the freeze-drying step to obtain a water-free product rich in oligorutin. All this information was directly taken from the lab and corresponds to primary data, as recommended. Moreover, background processes involved in the production of the inputs (i.e., water, chemicals, enzymes, nanoparticles, electricity, etc.) and ancillary activities (i.e., treatment of wastewater) were also included within the system boundaries. Therefore, it has been necessary to consider secondary data to complete the inventory tables for the background processes; the Ecoinvent database version $3.5^{30}$ has been considered as the main secondary data source. However, in the case of laccase and $[\mathrm{Ch}][\mathrm{DHph}]$ production, environmental profiles reported by Gilpin et al. ${ }^{31}$ and Zhang et al..$^{32}$ have been taken into account, respectively. Finally, in Sc4, research from Feijoo et al. ${ }^{33}$ has been considered for the identification of inventory data corresponding to the production of nanoparticles and laccase immobilization.

\section{RESULTS AND DISCUSSION}

Selection of the Most Promising ABS as a Reaction Medium. In order to identify an effective $A B S$ for the oligomerization of rutin, i.e., where the enzyme and the product should preferentially concentrate in opposite phases, preliminary studies to determine the partition of laccase and oligorutin were carried out with $\mathrm{ABS}$ formed by combinations of PEG with a molecular weight of $600 \mathrm{~g} \cdot \mathrm{mol}^{-1}$ (PEG 600) and different cholinium-based ILs, namely cholinium acetate ([Ch] $[\mathrm{Ac}])$, cholinium glycolate $([\mathrm{Ch}][\mathrm{Gly}])$, and cholinium dihydrogen phosphate $([\mathrm{Ch}][\mathrm{DHph}])$. Details on the PEG and ILs chemical structures are given in Figure S1. The separation performance of each ABS was evaluated by determining the extraction efficiency of each compound. Results on \%EE are given in Table S1. The ABS formed by PEG 600 and $[\mathrm{Ch}][\mathrm{Ac}],[\mathrm{Ch}][\mathrm{DHph}]$, or $[\mathrm{Ch}][\mathrm{Gly}]$ were previously characterized by Pereira et al. ${ }^{20}$ at $25^{\circ} \mathrm{C}$. Thus, biphasic mixture points were selected according to that work (weight fraction compositions being 40 wt \% PEG +40 wt $\%$ $[\mathrm{Ch}][\mathrm{Ac}], 30 \mathrm{wt} \% \mathrm{PEG}+30 \mathrm{wt} \%[\mathrm{Ch}][\mathrm{DHph}]$, and $40 \mathrm{wt} \%$ $\mathrm{PEG}+35$ wt $\%[\mathrm{Ch}][\mathrm{Gly}]$, where the lacking percentage value required to complete $100 \mathrm{wt} \%$ corresponds to water). At the conditions studied in this work, the top phase corresponds to 
the PEG-rich phase, while the bottom phase is mainly composed of the cholinium-based IL, except for the $[\mathrm{Ch}]$ [Ac]-PEG 600 ABS where phases display the opposite behavior, as previously reported. ${ }^{20}$

As shown in Table S1, the ABS composed of PEG 600 with $[\mathrm{Ch}][\mathrm{Gly}]$ did not allow the separation of oligorutin and laccase since both compounds preferentially partition to the IL-rich phase $\left(\% E E_{\text {oligorutin }}>90 \%\right.$ and $\% E E_{\text {laccase activity }} \sim 100$, both referred to the bottom phase). The ABS constituted by $[\mathrm{Ch}][\mathrm{Ac}]$ leads, however, to a successful separation of both compounds, with oligorutin being concentrated in the PEGrich phase $\left(\% E E_{\text {oligorutin }}>90\right)$ while laccase is enriched in the IL-rich phase $\left(\% E E_{\text {laccase activity }} \sim 100\right)$. Oligorutin preferentially migrated to the PEG-rich phase when the ABS was composed of $[\mathrm{Ch}][\mathrm{DHph}]$ or $[\mathrm{Ch}][\mathrm{Ac}]$. However, the behavior changed for $\mathrm{ABS}$ composed of $[\mathrm{Ch}][\mathrm{Gly}]$. The partition of (bio)molecules in ABS depends on dispersive interactions, electrostatic forces, hydrogen bonding, biomolecule size, and solubility. Indeed, comparing the $\log K_{\text {ow }}$ (octanol/water partition coefficient) values of $[\mathrm{Ch}][\mathrm{Ac}],[\mathrm{Ch}][\mathrm{Gly}]$, and $[\mathrm{Ch}][\mathrm{DHph}]$, the following the tendency was found: $[\mathrm{Ch}]$ [Gly] value of $-1.20,[\mathrm{Ch}][\mathrm{DHph}]$ value of -3.70 , and $[\mathrm{Ch}][\mathrm{Ac}]$ value of $-4.66,{ }^{20,34}$ meaning that $[\mathrm{Ch}][\mathrm{Gly}]$ is the most hydrophobic compound, which may be responsible for the change in the partition of oligorutin to the IL-rich phase.

The enzyme dramatically loses its activity within a few minutes in the $A B S$ composed of $[\mathrm{Ch}][\mathrm{Ac}]$, thus making it unsuitable as an integrated reaction-separation platform. Indeed, some acetate-type ILs have been reported to exert a negative effect upon the activity of different enzymes; in particular, for laccase, an interference in both the ABTS binding to the active site of the enzyme and in ABTS oxidation itself has been proposed, representing competitive and uncompetitive inhibition mechanisms, respectively. ${ }^{35}$ Moreover, the $\mathrm{pH}$ of the mixture point of this $\mathrm{ABS}$ has a high value ( $\mathrm{pH} \sim 9.4$; measured in this work), not adequate for laccase from T. versicolor, neither for its relative activity or stability. ${ }^{36}$

Remarkably, by using [Ch][DHph] and PEG 600 as ABS constituents, an appropriate separation of oligorutin to the polymer-rich phase ( 70 of $\left.\% E E_{\text {oligorutin }}\right)$ from laccase, which mainly migrates to the IL-rich phase ( 96 of $\% E E_{\text {laccase activity }}$ ), and with no decrease of the enzyme activity, was successfully achieved. Moreover, based on previous research, $[\mathrm{Ch}][\mathrm{DHph}]$ toxicity was defined as negligible, comparable to that of basic physiologic salts, ${ }^{37,38}$ thus reinforcing the biocompatibility of the studied ABS. Therefore, the ability of this system to be used in the development of an integrated reaction-separation process for rutin oligomerization and laccase recovery and reuse was further investigated, considering two approaches as described below.

Laccase-Catalyzed Rutin Oligomerization Using ABS as a Reaction Medium. In a first approach we studied the synthesis of oligorutin in a homogeneous medium (at $25^{\circ} \mathrm{C}$ ) to take advantage of the thermoreversible behavior of the selected ABS, previously described by Pereira et al. ${ }^{20}$ and here confirmed for a lower temperature interval (Figure S3). In this approach, the reaction can be carried out at in a homogeneous medium, after which an increase in temperature up to $40{ }^{\circ} \mathrm{C}$ leads to the creation of two phases and the simultaneous separation of the enzyme from the product. However, this approach did not lead to a high oligomerization yield (calculated based on equation S1) with a good enzyme activity performance (rutin conversion of $29 \%$ and relative enzyme activity loss of $28 \%$, as reported in Table S3).

To overcome this problem, a second approach was evaluated, consisting of the synthesis of oligorutin by laccase being performed in the biphasic regime (ABS) that would allow to simultaneously carry out the reaction, the product recovery, and the enzyme reuse without any further external stimuli. The biphasic system at room temperature was created by changes in the $\mathrm{pH}$ of the system, taking advantage of the $\mathrm{pH}$-driven reversibility of this ABS (Figure S5), achieved by the speciation of the IL anion. ${ }^{39}$ Preliminary tests were performed using ABS consisting of [Ch] [DHph] and PEG 600 at $\mathrm{pH} 4.5,5.5$, and 6.5 since the biphasic region is achieved at $\mathrm{pH}$ values above 4.5 , the already studied monophasic region being attributed to a $\mathrm{pH}$ value of 4.3 . Both temperature $(25$ ${ }^{\circ} \mathrm{C}$ ) and mixture composition (26.08 wt \% of PEG $+26.75 \mathrm{wt}$ $\%$ of $[\mathrm{Ch}][\mathrm{DHph}])$ were maintained unaltered as for the previous thermoreversible approach. Although a more alkaline $\mathrm{pH}$ would benefit rutin solubility, ${ }^{40}$ higher values were not considered since they could compromise the laccase stability/ activity. ${ }^{36}$ It must be noted that such a small change in $\mathrm{pH}$ from 4.3 to 4.5 led to a biphasic regime, which can be explained by the proximity of the mixture point to the binodal curve of $[\mathrm{Ch}][\mathrm{DHph}]-\mathrm{PEG} 600 \mathrm{ABS}$ at $\mathrm{pH} 4.3$ and $25^{\circ} \mathrm{C}$ (Figure S5). The oligomerization of rutin was then performed in these $\mathrm{ABS}$ at $25^{\circ} \mathrm{C}$ for $24 \mathrm{~h}$, and the rutin conversion and relative laccase activity (\%) were evaluated over time. Additionally, rutin stability at such $\mathrm{pH}$ values was also confirmed by reaction controls performed in the absence of laccase (rutin concentration after $24 \mathrm{~h}$ being higher than $93 \%$ for all $\mathrm{pH}$ values considered). The obtained results are summarized in Figure 1 (Table S4).

After $2 \mathrm{~h}$ of reaction, a remarkable enhancement in reaction kinetics was observed when the $\mathrm{pH}$ was increased from 4.5 to 6.5 , since the oligomerization yields change from $22 \%$ to $51 \%$, respectively (Figure 1 ). The same trend was observed for all

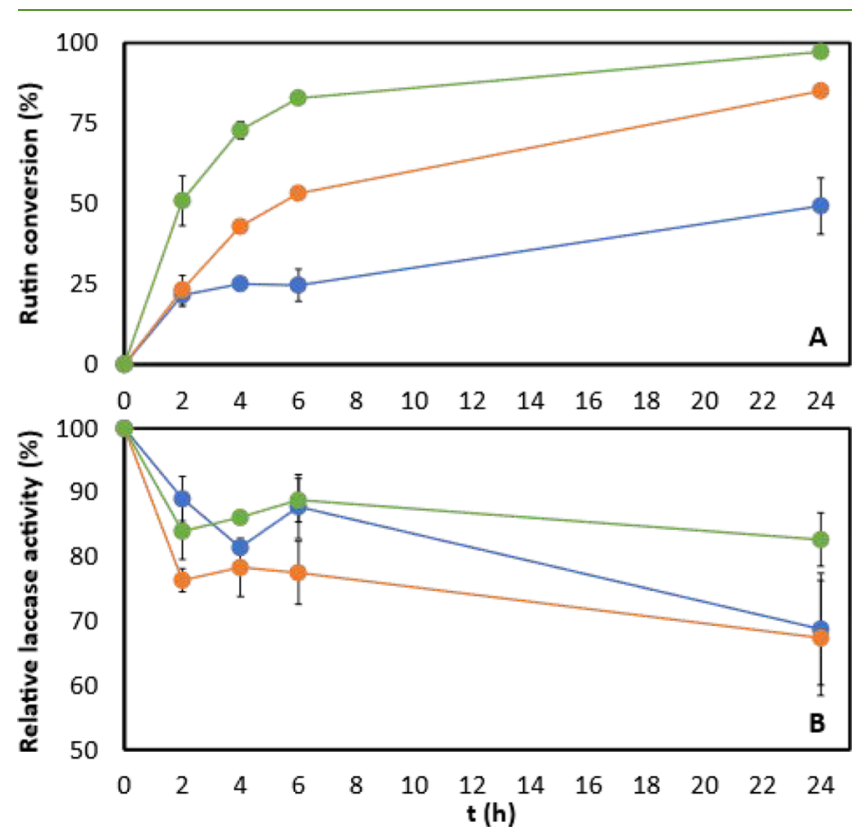

Figure 1. (A) Rutin conversion, \%, and (B) relative laccase activity, \%, over time for the oligomerization of rutin at $\mathrm{pH} 4.5$ (blue), 5.5 (orange), and 6.5 (green), using the $[\mathrm{Ch}][\mathrm{DHph}]-\mathrm{PEG} 600 \mathrm{ABS}$ in the biphasic regime at $25{ }^{\circ} \mathrm{C}$. 
reaction times evaluated, with these results being attributed to a better contact between the enzyme and its substrate due to higher rutin solubility at more alkaline $\mathrm{pH}$ values. ${ }^{40}$ Considering that $24 \mathrm{~h}$ of reaction led to the best oligomerization yield (97\%, $\mathrm{pH} 6.5$ ), this time was selected to evaluate the effect of $\mathrm{pH}$ upon the overall process. With the increase of $\mathrm{pH}$ from 4.5 to 6.5 , the rutin oligomerization yield reaches values close to $100 \%$ ( $\sim 2$-fold), while laccase activity decreases from $\sim 31$ to $17 \%$ (Figure 1). Thus, both rutin conversion and relative enzyme activity are enhanced using ABS with higher $\mathrm{pH}$ ( $\mathrm{pH}$ 6.5). Furthermore, the effect of $\mathrm{pH}$ upon oligorutin and laccase extraction efficiencies was also studied, as shown in Figure 2 (detailed data in Table S5), with a slight improvement occurring at $\mathrm{pH} 6.5$ for both oligorutin and laccase (69 of $\% E E_{\text {oligorutin }}$ and 91 of $\% E E_{\text {laccase activity }}$ ).

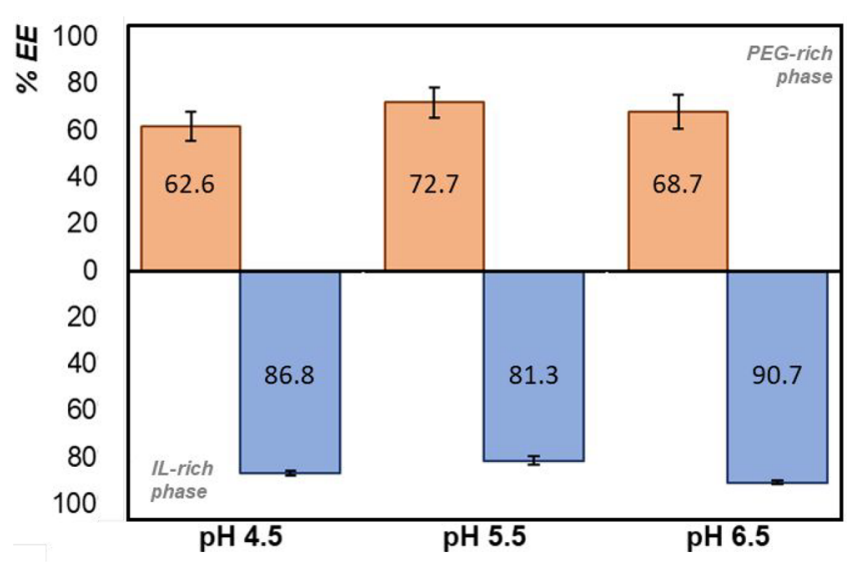

Figure 2. Oligorutin (orange bar) and laccase (blue bar) extraction efficiencies $(\% E E)$ in the $[\mathrm{Ch}][\mathrm{DHph}]-\mathrm{PEG} 600 \mathrm{ABS}$ at $\mathrm{pH} 4.5,5.5$, and 6.5 after $24 \mathrm{~h}$ of enzymatic reaction in the biphasic regime at 25 ${ }^{\circ} \mathrm{C}$.

Interestingly, when comparing the results obtained at $\mathrm{pH} 4.3$ in the monophasic regime (first approach considered in this work) to those reached when using an ABS in the biphasic regime at $\mathrm{pH} 4.5$, a remarkable improvement of the rutin conversion of $\sim 1.7$-fold was observed (rutin conversions of $29 \%$ and $49 \%$ for $\mathrm{pH}$ at 4.3 and 4.5 , respectively). Such a small change in $\mathrm{pH}$ alone cannot explain the increment observed; therefore, to better understand why rutin oligomerization was favored in a biphasic reaction medium, the influence of each phase composition on the oligorutin synthesis was evaluated. For this purpose, the reaction was performed in separated top and bottom phases at the optimal $\mathrm{pH}$ of 6.5. According to the results (Table S6 and Figure S6), rutin conversion, laccase activity, and reaction kinetics are improved when the reaction takes place in the $[\mathrm{Ch}][\mathrm{DHph}]$-rich phase, which can be explained by the positive effect of cholinium cations over both laccase stability and activity, as shown in the literature. ${ }^{18}$ After $24 \mathrm{~h}$ of reaction, the final enzyme activity was $10 \%$ higher in this phase than in the PEG-rich phase, reaching the complete oligomerization of rutin, while only $80 \%$ yield was achieved when the reaction was performed in the PEG-rich phase. Moreover, when the oligomerization was performed in the monophasic region of the ABS, the concentration of each $A B S$ constituent was 26.08 and 26.75 wt \% for PEG 600 and $[\mathrm{Ch}][\mathrm{DHph}]$, respectively, while in the $[\mathrm{Ch}][\mathrm{DHph}]$-rich phase the composition was 6.86 and 41.68 wt \% for PEG 600 and $[\mathrm{Ch}][\mathrm{DHph}]$ (Figure S7). These values reinforce the fact that high concentrations of $[\mathrm{Ch}][\mathrm{DHph}]$ improve laccase enzymatic performance. Additionally, and as mentioned before, rutin solubility benefits from the presence of organic solvents, ${ }^{1}$ meaning that the opposite PEG-rich phase (49.49 wt \% for PEG and 8.47 wt $\%$ for $[\mathrm{Ch}][\mathrm{DHph}])$ could increase the amount of rutin available to be transformed by laccase into oligorutin. The study of the extraction efficiency of rutin to [Ch][DHph] and PEG-rich phases was also performed, and the results (Table S5) show an $88 \%$ rutin extraction efficiency toward the PEG-rich phase, higher than that observed for oligorutin $(\sim 70 \%)$. This trend is somehow expected given rutin hydrophobicity. ${ }^{22}$ Consequently, when the reaction is carried out in the heterogeneous region of the ABS, i.e., in the presence of both immiscible phases, a higher solubility of rutin and an enhanced performance of the biocatalyst can be obtained. Furthermore, since the reaction occurs under continuous stirring, the higher activity of laccase in the biphasic medium can also be accounted for by the high availability of the interface, allowing better interactions between the substrate and the enzyme.

Recovery and Laccase Reuse. Based on the capacity of [Ch][DHph]-PEG $600 \mathrm{ABS}$ to act as a reaction medium for the oligomerization of rutin by laccase and taking into consideration its ability to separate the enzyme and oligomers, this $\mathrm{ABS}$ was then studied as an integrated reaction-separation

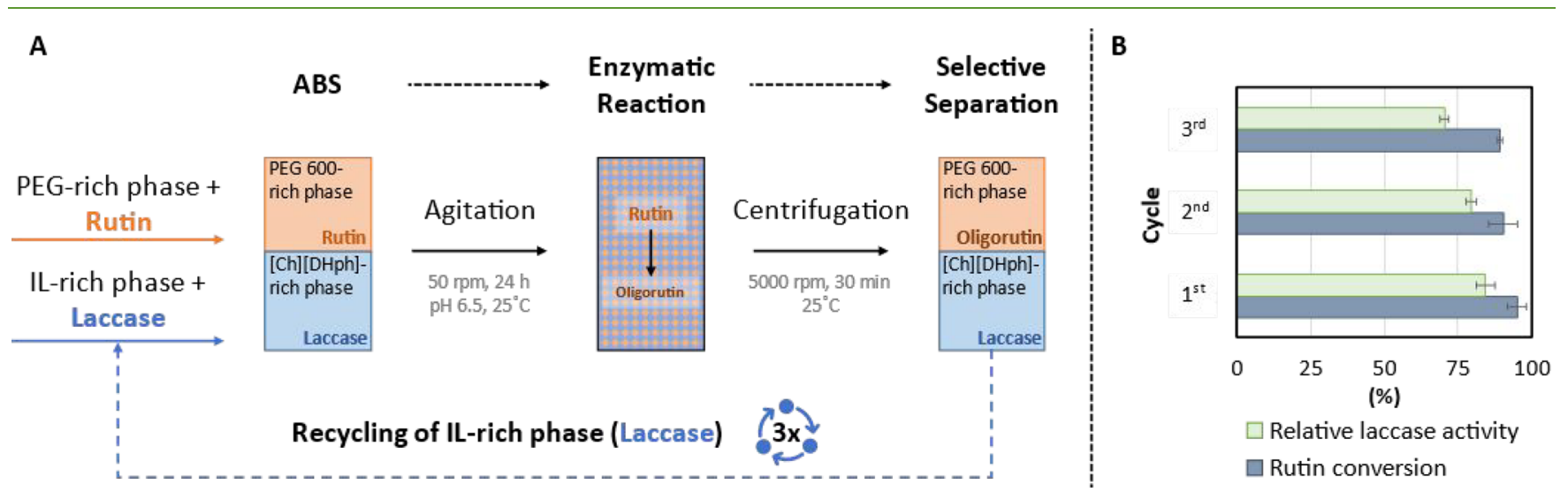

Figure 3. (A) Flowchart of the integrated reaction-separation process developed by applying ABS consisting of PEG 600 and [Ch][DHph], at pH 6.5 and $25{ }^{\circ} \mathrm{C}$, including the recycling of the laccase and the IL-rich phase. (B) Relative laccase activity and rutin conversion (\%) in three cycles of oligomerization reaction, comprised of both the recovery and the reuse of the enzyme and IL-rich phase. 
platform for three consecutive reaction cycles, allowing to confirm that laccase maintains its biocatalytic activity after the separation step. A scheme of the enzyme recovery/reuse process is illustrated in Figure 3A. After the first cycle of reaction, the synthesized oligorutin was enriched in the PEGrich top phase $\left(67 \% E E_{\text {oligorutin }}\right)$, which was then recovered by separating both phases. The IL-rich bottom phase containing laccase $\left(95 \% E E_{\text {laccase activity }}\right)$ was recovered and reused in a new biocatalytic reaction cycle. For the creation of novel ABS as reaction media to start the next cycle, a new polymer-rich phase containing adequate amounts of PEG and IL, namely 49.49 wt $\%$ of PEG $600+8.47$ wt \% of $[\mathrm{Ch}][\mathrm{DHph}]$, as obtained from the binodal curve (Table S7) and tie-line (Figure S7) data at $25{ }^{\circ} \mathrm{C}$ and $\mathrm{pH} 6.5$, was added to the recovered laccase-enriched bottom phase, and new rutin was provided to start the oligomerization reaction. This reactionseparation procedure was repeated in successive cycles, accounting for a total of 3 . Images illustrating the visual aspect of the end of the reaction $(24 \mathrm{~h})$ and both separated phases are provided in Figure S8. The results obtained (Figure 3B) show that it is possible to recover and reuse laccase, for at least three consecutive cycles, allowing noteworthy oligomerization yields of $95 \%$ in the first cycle, $91 \%$ in the second cycle, and $89 \%$ in the last cycle, since only a slight loss in the enzyme catalytic activity was observed during the reaction-separation cycles (Table S8). This small loss in enzymatic activity may be due to the time required for rutin polymerization $(\sim 25 \mathrm{~h})$ at room temperature $\left(25 \pm 2{ }^{\circ} \mathrm{C}\right)$ since previous studies demonstrated that laccase from $T$. versicolor loses $\sim 20 \%$ relative activity after being incubated at room temperature over $24 \mathrm{~h}$ at $\mathrm{pH} 7.0,{ }^{42}$ these operational conditions being similar to those used in this work ( $\mathrm{pH}$ 6.5). Moreover, laccase extraction efficiencies of $\sim 94 \%$ and oligorutin extraction efficiencies of $\sim 67 \%$ to opposite phases were maintained over the three consecutive cycles (Table S9).

When compared to recently described biocompatible processes for rutin oligomerization, ${ }^{8,22,40}$ the platform here designed allows the obtaining of both higher or comparable oligomerization yields under lower catalytic activity at mild conditions. For instance, Pivec et al. ${ }^{40}$ obtained a $57 \%$ rutin oligomerization yield using $5000 \mathrm{U} / \mathrm{L}$ of laccase activity. In our previous work involving the use of hydroethanolic reaction media, ${ }^{22}$ comparable rutin conversion to that obtained in this work (93\%) was obtained only when the enzyme activity was increased up to $10000 \mathrm{U} / \mathrm{L}$, while $1000 \mathrm{U} / \mathrm{L}$ accounted for a $70 \%$ oligomerization yield. However, contrary to these previous reports, ${ }^{22,40}$ the process developed in this work also allows the reutilization of laccase (and the $[\mathrm{Ch}][\mathrm{DHph}]$-rich phase), at least in three successive reaction-separation cycles as demonstrated, while maintaining outstanding production yields. To the best of our knowledge, there is only another recently published work studying laccase reuse in rutin oligomerization and biocompatible reaction media, based on ultrafiltration membrane technology to separate the enzyme and the oligomers produced. ${ }^{8}$ In that work, $\mathrm{pH} 6.0$ phosphate buffer was used as the reaction medium, and $\sim 100 \%$ rutin oligomerization yields were obtained under $1000 \mathrm{U} / \mathrm{L}$ laccase activity, performing three consecutive reaction-separation cycles, where laccase was successfully reused and accounting for a total activity loss of less than $20 \%$ at the end of the third cycle. Nonetheless, while this technology allowed lower enzyme activity losses than those observed in the current work, the use of a solid substrate under constant stirring and in contact with an ultrafiltration membrane could compromise the integrity of the membrane through erosion and fouling processes. This drawback could be avoided with the technology developed and proposed here .

Finally, tests on increasing the rutin initial concentration up to $10 \mathrm{~g} / \mathrm{L}$ (higher than those tested in previous works not involving organic cosolvents) were performed. The rutin conversion achieved after $24 \mathrm{~h}$ of reaction, using the proposed ABS-based technology, was higher than $93 \%$, while $\% E E$ for both oligorutin and laccase activity showed similar values to those observed in experiments involving $3 \mathrm{~g} / \mathrm{L}$ of rutin concentration (65\% and $92 \%$, respectively, Table S11). Therefore, these results support the hypothesis that this platform would be suitable for higher concentrations of other insoluble substrates, although further studies and optimization of the process would be required. Moreover, both the results obtained in consecutive cycles considering laccase reuse and the good oligorutin yield at higher substrate concentrations evince the robustness of the developed reaction-separation platform, which is crucial for the design of a sustainable flow process. It should be further remarked that although the complete isolation of oligorutin was not achieved in a single step, in a cyclic process the complete recovery of the product is not relevant since the final product present in the enzyme-rich phase, i.e., oligorutin, will be recycled together with the reused phase.

Oligorutin Characterization. As already reported in the literature, oligorutin shows improved bioactive and antioxidant properties when compared to the natural monomer rutin, namely better xanthine oxidase inhibitory activity, enhanced scavenging activity against biologically important radicals such as $\mathrm{NO}, \mathrm{O}_{2}$; or $\mathrm{OH}$; augmented $\mathrm{Fe}^{2+}$ chelating activity, etc. $8,40,43$ These properties, alongside with its remarkably increased aqueous solubility, boost the potential applications of this biosynthesized product in either food, pharmaceutical, or cosmetic industries. In this work, MALDI-TOF analysis of oligorutin produced in the current process (Figure S9) revealed a maximum degree of rutin polymerization of 7 , similar to that obtained in hydroethanolic medium. ${ }^{22}$ On the other hand, the antioxidant activity of oligorutin obtained in this work, determined by the TEAC (Trolox Equivalent Antioxidant Capacity) assay, shows a decrease of $\sim 55 \%$ in radical-scavenging activity when compared to rutin (Table S10), also similar to reductions observed in the previously described synthesis. ${ }^{22}$ Taking into account the straight relation between the flavonoid structure and their antioxidant properties, ${ }^{44,45}$ both the degree of polymerization and antioxidant capacity suggest that the oligorutin produced in $A B S$ is structurally similar to that obtained in previous works where a more extensive analysis of their properties and structure was performed, proposing that the possible bonds between different rutin units more likely happen between $\mathrm{C} 2{ }^{\prime}-\mathrm{C} 2^{\prime}$, $\mathrm{O}^{\prime}-\mathrm{C}^{\prime}$, and $\mathrm{C}^{\prime}-\mathrm{C}^{\prime}$ atoms present in the rutin monomer structure. $^{22,40}$

Recovery of PEG 600 and [Ch][DHph]. Rutin oligomers here produced in an $\mathrm{ABS}$ reaction medium were concentrated in a PEG-rich phase, this polymer being approved by the FDA to be used as a base or vehicle in foods, cosmetics, and pharmaceutical products (including injectable, rectal, topical, and nasal formulations). ${ }^{46}$ This PEG-rich phase also contains, as above-mentioned, $8.47 \mathrm{wt} \%[\mathrm{Ch}][\mathrm{DHph}]$, the toxicity of this IL being defined as negligible comparable to that of basic physiologic salts. ${ }^{37,38}$ Nevertheless, aiming to increase the 
oligorutin purity, the implementation of an ultrafiltration step to isolate oligorutin was also studied, further allowing the PEGrich phase recovery. As depicted in Table S12, ultrafiltration of diluted top oligorutin-rich phases caused an increase of 1.87 and 3.04-fold in oligorutin purity in the final freeze-dried product, with 1:2 and 1:4 aqueous dilutions, respectively. Indeed, by duplicating the dilution factor while retaining the same volume inside of the ultrafiltration cell, an increase of $\sim 20 \%$ PEG $600+[\mathrm{Ch}][\mathrm{DHph}]$ recovery was achieved $(\sim 70 \%$ recovery of PEG $600+[\mathrm{Ch}][\mathrm{DHph}]$ from the top phase), which could be used to partially formulate a novel top phase of the ABS by simply adding the lacking amount of both these compounds to reach the correct composition. Moreover, MALDI-TOF analysis of the retentate fraction shows signals corresponding mainly to oligorutin, while low molecular weight rutin oligomers appear in the permeate stream in which signals corresponding to PEG were more relevant (Figure S9).

Life-Cycle Assessment. Although biotechnology presents great opportunities for the development of production platforms that generate bioactive compounds that meet straightforward environmental protection goals, these novel production systems are not always in the path to environmental sustainability. ${ }^{47}$ In this regard, the overall biotechnological challenge must be confirmed considering the corresponding environmental assessment. For this reason, the environmental benefits associated with the ABS-based reaction-separation platform developed in this work (Sc1) were appraised by the Life Cycle Assessment (LCA) methodology and compared to three alternative processes allowing laccase reuse for producing oligorutin, briefly Sc2 involving the same ABS-based strategy but including an additional ultrafiltration step to reuse $[\mathrm{Ch}][\mathrm{DHph}]$ and PEG 600, Sc3 considering an enzymatic membrane reactor (EMR), ${ }^{8}$ and Sc4 using laccase immobilized onto magnetic nanoparticles (mNPs), ${ }^{29}$ as above-mentioned. Note that in Sc2, although a further dilution would allow higher PEG 600 and $[\mathrm{Ch}][\mathrm{DHph}]$ recovery (Table S12), data from 1:2 dilution studies was considered; this choice was based on the need for an additional step to reduce the water content in the recovered fraction obtained in the ultrafiltration process involving 1:4 dilution, which would imply an increase in electricity requirements and water consumption associated with polymer and ionic liquid recovery. The environmental profile of these processes was studied in terms of acidification (AC), eutrophication (EU), global warming (GW), ozone layer depletion (OD), and photochemical oxidation (PO), corresponding to five impact categories commonly analyzed in biotechnological studies. ${ }^{31,32,48}$ The main steps, inputs, outputs, and energy requirements of the different scenarios are schematized in Figure S10, with the inventory data sources summarized in Table S13.

According to the results obtained per gram of oligorutin (functional unit) for each scenario, there is a remarkable difference in the profiles regardless of the impact category considered for analysis, Scl being the most environmentally friendly strategy, as shown in Figure 4. These results evince that although the addition of an ultrafiltration step in Sc2 allowed the partial recovery of PEG 600 and [Ch][DHph], therefore reducing the consumption of chemicals, it does not overcome the impacts associated with the additional ultrafiltration step required when compared to $\mathrm{Sc}$. Moreover, impact reductions higher than $97 \%$ are identified in all

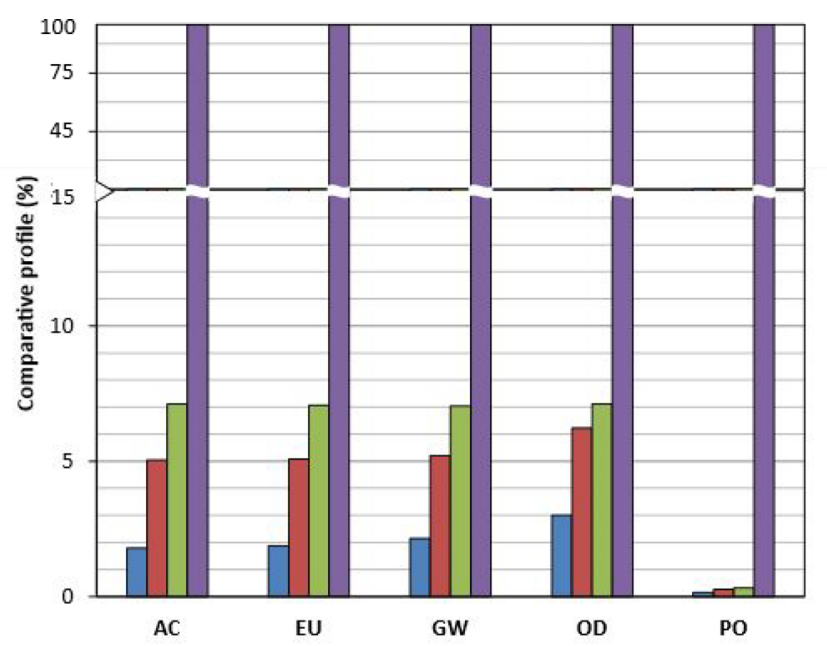

Figure 4. Comparative profiles between the different oligorutin production scenarios considered for analysis in terms of acidification (AC), eutrophication (EU), global warming (GW), ozone layer depletion (OD), and photochemical oxidation (PO). Blue bar: Sc1; red bar: Sc2; green bar: Sc3; purple bar: Sc4.

categories for $\mathrm{Sc} 1$ compared to $\mathrm{Sc} 4$, the scenario where mNPs are involved to allow laccase reuse, $\mathrm{Sc} 4$ being the process with the worst environmental profile. Specifically, for the platform developed in this work $(\mathrm{Sc1})$, the following results were obtained (Table S14): $5.41 \mathrm{~g}$ of $\mathrm{SO}_{2}$ equiv (AC), $1.30 \mathrm{~g}$ of $\mathrm{PO}_{4}{ }^{3-}$ equiv (EU), $0.80 \mathrm{~kg}$ of $\mathrm{CO}_{2}$ equiv (GW), $0.06 \mathrm{mg}$ of CFC-11 equiv (OD), and $0.39 \mathrm{~g}$ of $\mathrm{C}_{2} \mathrm{H}_{4}$ equiv (PO).

The rationale behind these impacts is mainly associated with electricity requirements (based on fossil resources), as can be observed in Figure S11, specifically relying on the freeze-drying step. Indeed, according to the data, electricity requirements in Sc1 are $61 \%, 81 \%$, and $99 \%$ lower than in Sc2, Sc3, and Sc4, respectively. It is important to remark that although freezedrying implies high electricity consumption in all scenarios, the stirring is the environmental hotspot (i.e., the process responsible for the highest contributions to the global profile) in Sc1 and Sc2, observing an increase of $2.44 \mathrm{kWh} / \mathrm{g}$ oligorutin in Sc2, associated with the PEG 600 and [Ch][DHph] recovery step. However, differences related to the main source of contributing burdens to the PO category were spotted, especially in Sc4, where the electricity requirement was not the hotspot but the uncontrolled emission of ethanol (which represents $30 \%$ of the volume of the reaction medium) into the air in the freeze-drying step. Indeed, this emission represented $95 \%$ of the total contributing substances to the PO category. It must be stated that this impact would be considerably lower if this process was further optimized by including an ethanol recovery step, reducing both ethanol consumption and emission. However, a freeze-drying step was assumed for this LCA study (time of freeze-drying based on primary experimental data) to reach a fully dry final product, therefore making this process more easily comparable to the different scenarios.

If electricity-related impacts were withdrawn from this analysis (Figure S12), the production of chemicals, especially PEG 600 in Sc1 and Sc2, would play a key role in all the impact categories studied. Nevertheless, in Sc4, the most important production of chemicals responsible for all the impacts would be the required ethanol (contributing ratios of 
more than $90 \%$ in all the categories of the impacts associated with chemicals production, as can be observed in Figure S13).

Finally, the normalization factors from the selected method of analysis have been considered to establish a final ranking of scenarios. This approach, although contemporary, is widely used and well recognized as it allows the direct comparison between equivalent systems. ${ }^{49}$ The scores estimated for the scenarios are $0.502 \times 10^{-13}, 1.27 \times 10^{-13}, 1.76 \times 10^{-13}$, and $49.4 \times 10^{-13}$, for Sc1, Sc2, Sc3, and Sc4, respectively. Accordingly, Sc1 can be considered the best scenario of oligorutin production allowing laccase reuse from an environmental perspective.

\section{CONCLUSION}

ABS composed of biocompatible ILs and polymers were here demonstrated to act as an environmentally friendly, efficient, and integrated reaction-separation platform to carry out the biocatalytic conversion of rutin into oligorutin (a compound with potential commercial interest), further allowing the reuse of the enzyme without compromising high production yields. Overall, remarkable results are obtained when the reaction takes place in the biphasic regime, benefiting from both an increased substrate solubility and an enhanced catalytic performance. These results open up a pathway for the use of IL-based ABS as sustainable platforms for integrated biocatalytic processes.

\section{ASSOCIATED CONTENT}

\section{SI Supporting Information}

The Supporting Information is available free of charge at https://pubs.acs.org/doi/10.1021/acssuschemeng.1c03399.

Preliminary study on oligorutin and laccase separation in biocompatible ABS; protocols used concerning HPLC, MALDI-TOF, and antioxidant activity (TEAC) determination and spectrophotometric measurements; methodology for ABS diagrams and tie-line determination and results obtained; detailed information on rutin

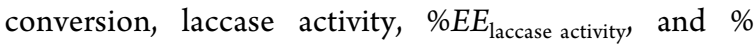
$E E_{\text {oligorutin }}$ for the different experiments; results on the recovery of PEG 600 and $[\mathrm{Ch}][\mathrm{DHph}]$ from the top phases; data needed for LCA analysis (PDF)

\section{AUTHOR INFORMATION}

\section{Corresponding Authors}

Gemma Eibes - CRETUS, Department of Chemical

Engineering, Universidade de Santiago de Compostela, 15782 Santiago de Compostela, Spain; orcid.org/0000-00032432-6323; Phone: +34 8818 16016;

Email: gemma.eibes@usc.es

Ana P. M. Tavares - CICECO-Aveiro Institute of Materials, Chemistry Department, University of Aveiro, 3810-193 Aveiro, Portugal; (1) orcid.org/0000-0001-9128-6275; Phone: +351 234401 520; Email: aptavares@ua.pt

\section{Authors}

Abel Muñiz-Mouro - CRETUS, Department of Chemical Engineering, Universidade de Santiago de Compostela, 15782 Santiago de Compostela, Spain; (1) orcid.org/0000-00023199-5958

Ana M. Ferreira - CICECO-Aveiro Institute of Materials, Chemistry Department, University of Aveiro, 3810-193 Aveiro, Portugal; 이이.org/0000-0003-3057-5019
João A. P. Coutinho - CICECO-Aveiro Institute of Materials, Chemistry Department, University of Aveiro, 3810-193 Aveiro, Portugal; (i) orcid.org/0000-0002-3841$743 \mathrm{X}$

Mara G. Freire - CICECO-Aveiro Institute of Materials, Chemistry Department, University of Aveiro, 3810-193

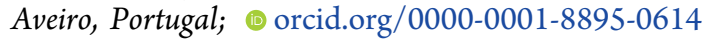

Patricia Gullón - Laboratorio C.A.C.T.I.-PQ Tecnolóxico de Galicia, Tecnopole, 32901 San Cibrao das Viñas, Ourense, Spain

Sara González-García - CRETUS, Department of Chemical Engineering, Universidade de Santiago de Compostela, 15782 Santiago de Compostela, Spain

Complete contact information is available at:

https://pubs.acs.org/10.1021/acssuschemeng.1c03399

\section{Author Contributions}

The manuscript was written through contributions of all authors. G.E., A.M.F., A.P.M.T, M.G.F., S.G-G., and A.M-M. conceived and designed the experiments. A.M-M. performed all the experiments. A.M-M., G.E., A.M.F., A.P.M.T, M.G.F., S.G-G., P.G., and J.A.P.C. analyzed the data. All authors contributed to the writing of this paper. All authors have given approval to the final version of the manuscript.

\section{Notes}

The authors declare no competing financial interest.

\section{ACKNOWLEDGMENTS}

This research was supported by the Spanish Government (AEI) through the RTI2018-094482-J-I00 project. This work was developed within the scope of the project CICECO-Aveiro Institute of Materials, UIDB/50011/2020 \& UIDP/50011/ 2020, financed by national funds through the Portuguese Foundation for Science and Technology/MCTES. The authors A.M.-M. and G.E. belong to the Galician Competitive Research Group (GRC). The programme is cofunded by FEDER (UE). The authors acknowledge the use of RIAIDTUSC analytical facilities. A.P.M.T. thanks the FCT for the research contract CEECIND/2020/01867. G.E. thanks the Spanish MICIU for her Ramón y Cajal contract (RYC2018024846-I). A.M.-M. thanks the Programa de axudas á etapa predoutoral da Xunta de Galicia (ED481A-2018/023).

\section{REFERENCES}

(1) Gullón, B.; Lú-Chau, T. A.; Moreira, M. T.; Lema, J. M.; Eibes, G. Rutin: A Review on Extraction, Identification and Purification Methods, Biological Activities and Approaches to Enhance Its Bioavailability. Trends Food Sci. Technol. 2017, 67, 220-235.

(2) Rufa, L.; Yunning, Z.; Rui, W.; Jianying, L. A Study on the Extract of Tartary Buckwheat. I. Toxicological Safety of the Extract of Tartary Buckwheat. Adv. Buckwheat Res. Proceeding VIII Int. Symposium Buckwheat; 2001; pp 602-607; https://citeseerx.ist.psu.e$\mathrm{du} /$ viewdoc/download?doi=10.1.1.602.5471 \& rep=rep $1 \&$ type=pdf\#: : :text $=$ The $\% 20$ toxicological\%20safety $\% 20$ of $\% 20$ the, The \%20extract\%20has\%20no\%20toxicity.\&text=Buckwheat\%20belongs \%20to\%20the\%20family\%20Polyganaceae (accessed July 3, 2021).

(3) Sharma, S.; Sahni, J.; Ali, J.; Baboota, S. Patent Perspective for Potential Antioxidant Compounds-Rutin and Quercetin. Recent Pat. Nanomed. 2013, 3 (1), 62-68.

(4) NIH. Dietary Supplement Label Database. https://www.dsld.nlm. nih.gov/dsld/index.jsp (accessed May 10, 2021).

(5) Rothwell, J. A.; Day, A. J.; Morgan, M. R. A. Experimental Determination of Octanol - Water Partition Coefficients of 
Quercetin and Related Flavonoids. J. Agric. Food Chem. 2005, 53 (11), $4355-4360$.

(6) Hollmann, F.; Arends, I. W. C. E. Enzyme Initiated Radical Polymerizations. Polymers (Basel, Switz.) 2012, 4 (1), 759-793.

(7) Jeon, J. R.; Baldrian, P.; Murugesan, K.; Chang, Y. S. LaccaseCatalysed Oxidations of Naturally Occurring Phenols: From in Vivo Biosynthetic Pathways to Green Synthetic Applications. Microb. Biotechnol. 2012, 5 (3), 318-332.

(8) Muñiz-Mouro, A.; Gullón, B.; Lu-Chau, T. A.; Eibes, G. Green and Sustainable Synthesis of Oligorutin Using an Enzymatic Membrane Reactor: Process Optimization. Food Bioprod. Process. 2020, 124, 434-444.

(9) Anthoni, J.; Lionneton, F.; Wieruszeski, J. M.; Magdalou, J.; Engasser, J. M.; Chebil, L.; Humeau, C.; Ghoul, M. Investigation of Enzymatic Oligomerization of Rutin. Rasayan J. Chem. 2008, 1 (4), 718-731 http://www.rasayanjournal.co.in/vol-1/issue-4/2.pdf (accessed July 3, 2021).

(10) Ba, S.; Arsenault, A.; Hassani, T.; Jones, J. P.; Cabana, H. Laccase Immobilization and Insolubilization: From Fundamentals to Applications for the Elimination of Emerging Contaminants in Wastewater Treatment. Crit. Rev. Biotechnol. 2013, 33 (4), 404-418.

(11) Fernández-Fernández, M.; Sanromán, M. Á.; Moldes, D. Recent Developments and Applications of Immobilized Laccase. Biotechnol. Adv. 2013, 31 (8), 1808-1825.

(12) Expanding Biocatalysis for a Sustainable Future. Nat. Catal. 2020, 3 (3), 179-180. .

(13) Arca-Ramos, A.; Eibes, G.; Moreira, M. T.; Feijoo, G.; Lema, J. M. Surfactant-Assisted Two Phase Partitioning Bioreactors for Laccase-Catalyzed Degradation of Anthracene. Process Biochem. 2012, 47 (7), 1115-1121.

(14) Arca-Ramos, A.; Eibes, G.; Moreira, M. T.; Feijoo, G.; Lema, J. M. Vegetable Oils as NAPLs in Two Phase Partitioning Bioreactors for the Degradation of Anthracene by Laccase. Chem. Eng. J. 2014, 240, 281-289.

(15) Capela, E. V.; Santiago, A. E.; Rufino, A. F. C. S.; Tavares, A. P. M.; Pereira, M. M.; Mohamadou, A.; Aires-Barros, M. R.; Coutinho, J. A. P.; Azevedo, A. M.; Freire, M. G. Sustainable Strategies Based on Glycine-Betaine Analogue Ionic Liquids for the Recovery of Monoclonal Antibodies from Cell Culture Supernatants. Green Chem. 2019, 21 (20), 5671-5682.

(16) Silvério, S. C.; Rodríguez, O.; Tavares, A. P. M.; Teixeira, J. A.; MacEdo, E. A. Laccase Recovery with Aqueous Two-Phase Systems: Enzyme Partitioning and Stability. J. Mol. Catal. B: Enzym. 2013, 87, $37-43$.

(17) Ferreira, A. M.; Passos, H.; Okafuji, A.; Tavares, A. P. M.; Ohno, H.; Freire, M. G.; Coutinho, J. A. P. An Integrated Process for Enzymatic Catalysis Allowing Product Recovery and Enzyme Reuse by Applying Thermoreversible Aqueous Biphasic Systems. Green Chem. 2018, 20 (6), 1218-1223.

(18) Capela, E. V.; Valente, A. I.; Nunes, J. C. F.; Magalhães, F. F.; Rodríguez, O.; Soto, A.; Freire, M. G.; Tavares, A. P. M. Insights on the Laccase Extraction and Activity in Ionic-Liquid-Based Aqueous Biphasic Systems. Sep. Purif. Technol. 2020, 248 (April), 117052.

(19) Younes, M.; Aggett, P.; Aguilar, F.; Crebelli, R.; Dusemund, B.; Filipič, M.; Frutos, M. J.; Galtier, P.; Gott, D.; Gundert-Remy, U. Refined Exposure Assessment of Polyethylene Glycol (E 1521) from Its Use as a Food Additive. EFSA J. 2018, 16 (6), No. e05293.

(20) Pereira, J. F. B.; Kurnia, K. A.; Cojocaru, O. A.; Gurau, G.; Rebelo, L. P. N.; Rogers, R. D.; Freire, M. G.; Coutinho, J. A. P. Molecular Interactions in Aqueous Biphasic Systems Composed of Polyethylene Glycol and Crystalline vs. Liquid Cholinium-Based Salts. Phys. Chem. Chem. Phys. 2014, 16 (12), 5723-5731.

(21) Quental, M. V.; Caban, M.; Pereira, M. M.; Stepnowski, P.; Coutinho, J. A. P.; Freire, M. G. Enhanced Extraction of Proteins Using Cholinium-Based Ionic Liquids as Phase-Forming Components of Aqueous Biphasic Systems. Biotechnol. J. 2015, 10 (9), 1457-1466.

(22) Muñiz-Mouro, A.; Gullón, B.; Lú-Chau, T.; Moreira, M.; Lema, J.; Eibes, G. Laccase Activity as an Essential Factor in the Oligomerization of Rutin. Catalysts 2018, 8 (8), 321.
(23) Yuan, H.; Chen, L.; Cao, Z.; Hong, F. F. Enhanced Decolourization Efficiency of Textile Dye Reactive Blue 19 in a Horizontal Rotating Reactor Using Strips of BNC-Immobilized Laccase: Optimization of Conditions and Comparison of Decolourization Efficiency. Biochem. Eng. J. 2020, 156, 107501.

(24) Zimmermann, Y.-S.; Shahgaldian, P.; Corvini, P. F. X.; Hommes, G. Sorption-Assisted Surface Conjugation: A Way to Stabilize Laccase Enzyme. Appl. Microbiol. Biotechnol. 2011, 92 (1), $169-178$.

(25) Anthoni, J.; Chebil, L.; Lionneton, F.; Magdalou, J.; Humeau, C.; Ghoul, M. Automated Analysis of Synthesized Oligorutin and Oligoesculin by Laccase. Can. J. Chem. 2011, 89 (8), 964-970.

(26) Gullón, B.; Gullón, P.; Lú-Chau, T. A.; Moreira, M. T.; Lema, J. M.; Eibes, G. Optimization of Solvent Extraction of Antioxidants from Eucalyptus Globulus Leaves by Response Surface Methodology: Characterization and Assessment of Their Bioactive Properties. Ind. Crops Prod. 2017, 108 (June), 649-659.

(27) PRé Consultants. Simapro Database Manual Methods Library; 2020.

(28) Guinee, J. B.; Gorrée, M.; Heijungs, R.; Huppes, G.; Kleijn, R.; de Koning, A.; van Oers, L.; Wegener Sleeswijk, A.; Suh, S.; Udo de Haes, H. A.; et al. Handbook on Life Cycle Assessment Operational Guide to the ISO Standards. Int. J. Life Cycle Assess. 2002, 7 (5), 311.

(29) Moldes-Diz, Y.; Gamallo, M.; Eibes, G.; Vargas-Osorio, Z.; Vazquez-Vazquez, C.; Feijoo, G.; Lema, J. M.; Moreira, M. T. Development of a Superparamagnetic Laccase Nanobiocatalyst for the Enzymatic Biotransformation of Xenobiotics. J. Environ. Eng. 2018, 144 (3), No. 04018007.

(30) Wernet, G.; Bauer, C.; Steubing, B.; Reinhard, J.; Moreno-Ruiz, E.; Weidema, B. The Ecoinvent Database Version 3 (Part I): Overview and Methodology. Int. J. Life Cycle Assess. 2016, 21 (9), $1218-1230$.

(31) Gilpin, G. S.; Andrae, A. S. G. Comparative Attributional Life Cycle Assessment of European Cellulase Enzyme Production for Use in Second-Generation Lignocellulosic Bioethanol Production. Int. J. Life Cycle Assess. 2017, 22 (7), 1034-1053.

(32) Zhang, Z.; Liu, Y.; Dai, Y.; Zhang, H.; Chen, Z.; Shen, Y.; Zhu, Z.; Wang, Y. Life Cycle Environmental Implications of Ionic-LiquidBased Carbon Capture and Storage Processes and Its Alternative Improvement Cases. ACS Sustainable Chem. Eng. 2020, 8 (49), 18106-18113.

(33) Feijoo, S.; González-García, S.; Moldes-Diz, Y.; VázquezVázquez, C.; Feijoo, G.; Moreira, M. T. The Environmental Impact of Magnetic Nanoparticles under the Perspective of Carbon Footprint. In Environmental Carbon Footprints: Industrial Case Studies; Elsevier Inc.: Amsterdam, Netherlands, 2017; pp 45-77.

(34) Cumming, H.; Rücker, C. Octanol-Water Partition Coefficient Measurement by a Simple 1H NMR Method. ACS Omega 2017, 2 (9), 6244-6249.

(35) Stevens, J. C.; Rodgers, D. W.; Dumon, C.; Shi, J. Characterization and Enzyme Engineering of a Hyperthermophilic Laccase Toward Improving Its Activity in Ionic Liquid. Front. Energy Res. 2020, 8 (July), 1-9.

(36) Lloret, L.; Eibes, G.; Moreira, M. T.; Feijoo, G.; Lema, J. M. On the Use of a High-Redox Potential Laccase as an Alternative for the Transformation of Non-Steroidal Anti-Inflammatory Drugs (NSAIDs). J. Mol. Catal. B: Enzym. 2013, 97, 233-242.

(37) Weaver, K. D.; Kim, H. J.; Sun, J.; MacFarlane, D. R.; Elliott, G. D. Cyto-Toxicity and Biocompatibility of a Family of Choline Phosphate Ionic Liquids Designed for Pharmaceutical Applications. Green Chem. 2010, 12 (3), 507-551.

(38) Foureau, D. M.; Vrikkis, R. M.; Jones, C. P.; Weaver, K. D.; Macfarlane, D. R.; Salo, J. C.; Mckillop, I. H.; Elliott, G. D. In Vitro Assessment of Choline Dihydrogen Phosphate (CDHP) as a Vehicle for Recombinant Human Interleukin-2 (RhIL-2). Cell. Mol. Bioeng. 2012, 5 (4), 390-401.

(39) Ferreira, A. M.; Cláudio, A. F. M.; Válega, M.; Domingues, F. M. J.; Silvestre, A. J. D.; Rogers, R. D.; Coutinho, J. A. P.; Freire, M. G. Switchable (PH-Driven) Aqueous Biphasic Systems Formed by 
Ionic Liquids as Integrated Production-Separation Platforms. Green

Chem. 2017, 19 (12), 2768-2773.

(40) Pivec; Kargl; Maver; Bračič; Elschner; Žagar; Gradišnik; Kleinschek. Chemical Structure-Antioxidant Activity Relationship of Water-Based Enzymatic Polymerized Rutin and Its Wound Healing Potential. Polymers (Basel, Switz.) 2019, 11 (10), 1566.

(41) Bento, R. M. F.; Almeida, M. R.; Bharmoria, P.; Freire, M. G.; Tavares, A. P. M. Improvements in the Enzymatic Degradation of Textile Dyes Using Ionic-Liquid-Based Surfactants. Sep. Purif. Technol. 2020, 235, 116191.

(42) Arca-Ramos, A.; Ammann, E. M.; Gasser, C. A.; Nastold, P.; Eibes, G.; Feijoo, G.; Lema, J. M.; Moreira, M. T.; Corvini, P. F. X. Assessing the Use of Nanoimmobilized Laccases to Remove Micropollutants from Wastewater. Environ. Sci. Pollut. Res. 2016, 23 (4), 3217-3228.

(43) Kurisawa, M.; Chung, J. E.; Uyama, H.; Kobayashi, S. Enzymatic Synthesis and Antioxidant Properties of Poly(Rutin). Biomacromolecules 2003, 4 (5), 1394-1399.

(44) Burda, S.; Oleszek, W. Antioxidant and Antiradical Activities of Flavonoids. J. Agric. Food Chem. 2001, 49 (6), 2774-2779.

(45) Heim, K. E.; Tagliaferro, A. R.; Bobilya, D. J. Flavonoid Antioxidants: Chemistry, Metabolism and Structure-Activity Relationships. J. Nutr. Biochem. 2002, 13 (10), 572-584.

(46) Harris, J. M.; Chess, R. B. Effect of Pegylation on Pharmaceuticals. Nat. Rev. Drug Discovery 2003, 2 (3), 214-221.

(47) Bello, S.; Pérez, N.; Kiebist, J.; Scheibner, K.; Sánchez Ruiz, M. I.; Serrano, A.; Martínez, Á. T.; Feijoo, G.; Moreira, M. T. Early-Stage Sustainability Assessment of Enzyme Production in the Framework of Lignocellulosic Biorefinery. J. Cleaner Prod. 2021, 285, 125461.

(48) Gullón, P.; Gullón, B.; Dávila, I.; Labidi, J.; Gonzalez-Garcia, S. Comparative Environmental Life Cycle Assessment of Integral Revalorization of Vine Shoots from a Biorefinery Perspective. Sci. Total Environ. 2018, 624, 225-240.

(49) Kalbar, P. P.; Birkved, M.; Nygaard, S. E.; Hauschild, M. Weighting and Aggregation in Life Cycle Assessment: Do Present Aggregated Single Scores Provide Correct Decision Support? J. Ind. Ecol. 2017, 21 (6), 1591-1600. 